\title{
Serial heart rate changes in rats inoculated by conjunctival instillation of Trypanosoma cruzi obtained from bug faeces
}

\author{
Alterações do ritmo cardíaco de ratos infectados pela via conjuntival por \\ Trypanosoma cruzi obtidos de fezes de triatomíneos
}

\author{
Adalinda Ollarves, Diego F. Dávila, Carlos F. Gottberg and Paolo Ramoni-Perazzi
}

\begin{abstract}
The cardiac effects of experimentally induced myocarditis, when the parasite is obtained from mouse blood, are well known. However, the consequences of the infection when the parasites are obtained from bug faeces are less well defined. In the present investigation, we have used the " $Y$ " strain of Trypanosoma cruzi, which was maintained in Rhodnius prolixus by repeated passages in mice. The faeces of 30 infected bugs were collected, the number of parasites counted and 4,000 parasites inoculated by the conjunctival route in 60 rats. Twenty-nine other rats received faeces from noninfected bugs (sham-inoculated controls) and 40 were used as normal controls. The heart rate of the three groups of animals was recorded under general anesthesia with ether. The heart rate, at day 0 pre-inoculation, was similar in the three groups of animals (Controls: $379 \pm 27$ beats/min Mean \pm SD; Sham-inoculated: $366 \pm 31$; Infected: $351 \pm 29$ ) ( $p>0.05)$. In the infected animals, the mean heart rate began to increase significantly by day 12 following infection ( $375 \pm 31$ ), reaching the highest values between days 18 (390 $\pm 33)$ and $21(403 \pm 33)$ and returned to baseline by day $30(359 \pm 28)(p<0.05)$. The heart rate changes were statistically different from those observed in the sham-inoculated controls and in the control animals. Therefore, these heart rate changes were provoked by the Trypanosoma cruzi-induced infection. Thus, it appears that irrespective of the source of the parasite and route of inoculation Trypanosoma cruzi acute infection provokes a transient sinus tachycardia.
\end{abstract}

Key-words: Trypanosoma cruzi. Conjunctival infection. Experimental Chagas' infection. Heart rate. Autonomic dysfunction.

Resumo Os efeitos da miocardite chagásica experimental, produzida por Trypanosoma cruzi proveniente do sangue de camundongos são bem conhecidos. O mesmo não ocorre quando a inoculação é feita com Trypanosoma cruzi proveniente de fezes do vetor. No presente estudo, usamos a variedade " $Y$ " do Trypanosoma cruzi mantida em Rodhnius prolixus por repetidas passagens em camundongos. As fezes de 30 insetos parasitados foram coletadas e contados os parasitas. O estudo foi desenvolvido em três grupos de ratos. O primeiro, controle, formado por 40 animais, o segundo, por 29 animais que receberam fezes de insetos não infectados (controle falso inoculado) e o terceiro grupo constituído por 60 ratos inoculados com 4.000 parasitas, por via conjuntival. Em todos os animais, após anestesia geral, registrou-se a freqüência cardíaca (FC). Esta, antes da inoculação, era similar nos infectados e nos controles (controle $379 \pm 27 \mathrm{bpm}$; falso inoculado: $366 \pm 31 \mathrm{bpm}$; infectado $351 \pm 29 \mathrm{bpm}$ ). No $12^{\circ}$ dia após a infecção, a FC no grupo chagásico começou a se elevar ( $375 \pm 31 \mathrm{bpm})$ atingindo seu valor máximo entre os dias $18(390 \pm 33 \mathrm{bpm})$ e $21(403 \pm 33 \mathrm{bpm})$. No 33ㅇdia pós-infecção, a FC retornou ao valor basal inicial. Nos grupos controles, não se detectaram alterações da FC. O estudo estatístico mostrou que as variações da FC, no grupo infectado, foram estatisticamente diferentes das detectadas nos outros grupos. Conclui-se que a infecção pelo Trypanosoma cruzi, em ratos, produz taquicardia sinusal transitória, independente da fonte do parasita e da via de inoculação.

Palavras-chaves: Trypanosoma cruzi. Infecção conjuntival. Infecção chagásica experimental. Ritmo cardíaco. Disfunção autonômica.

\footnotetext{
Departamento de Biología y Centro de Investigaciones Cardiovasculares de la Universidad de Los Andes, Mérida, Venezuela. Supported in part by Projects № M-354-90 and C-534-91 CDCH-T-ULA.

Address to: Dr. Diego F. Dávila. Centro de Investigaciones Cardiovasculares. Apartado Postal 590, Mérida,Venezuela

Fax: 05174403230

e-mail: diegod@ing.ula.ve

Recebido para publicação em 18/12/97
} 
The heart is normally under control of the sympathetic and parasympathetic divisions of the autonomic nervous system ${ }^{1922}$. The predominance of the former is considered to have adverse effects, whereas the latter would be protective ${ }^{1624}$. Moreover, in humans with advanced heart disease ${ }^{17}$, the baseline heart rate is directly related to the activity of the sympathetic nervous system on the sinus node, and the parasympathetic influence is markedly attenuated.

The mechanism(s) by which Trypanosoma cruzi provokes myocardial damage is still the subject of intense research and controversy2 111213142327 . In the early 1950's, Fritz Köberle ${ }^{20}$ postulated that, Trypanosoma cruzi-induced myocarditis selectively and irreversibly destroyed the cardiac parasympathetic neurons during the acute phase of the disease. Under this particular condition, the myocardium of patients with Chagasic heart disease is chronically exposed to a sympathetic predominance, which would be responsible for the relentless progression of myocardial damage.

In laboratory animals, selective cardiac parasympathetic denervation induces a persistent increment in the baseline heart rate (i.e., sinus tachycardia) ${ }^{192225}$. However, in rats with Trypanosoma cruzi-induced myocarditis, the sinus tachycardia is transient ${ }^{18}$ and limited to the acute stage of the inflammatory process ${ }^{29}$. In these experimental observations, a suspension of mouse-blood trypanosomes was inoculated intraperitoneally. Bug metacyclic trypanosomes from bug faeces, innoculated by conjunctival instillation, are more infective than flagellates from mouse blood ${ }^{33}$. Since myocardial and neuronal damage appear to be directly related to the intensity of the inflammatory process ${ }^{21}{ }^{28}$, we have now studied the effects, of bug metacyclic trypanosomes and of a route closer to how natural infection occurs, on the heart rate of infected rats in comparison to sham-inoculated and normal animals.

\section{MATERIAL AND METHODS}

One hundred and twenty female rats aged approximately 4 months were used. They were separated into 3 groups. Sixty rats were inoculated by the conjunctival route with 4,000 parasites ("Y" strain). Twenty animals were used as sham-inoculated controls and 40 as normal controls.

The parasites were obtained as follows: the "Y" strain of Trypanosoma cruzi was maintained in Rhodnius prolixus and by repeated passages in mice. The faeces of 30 infected bugs were collected and the number of parasites counted according to Brenner ${ }^{7}$. Sixty rats were anesthetized with intraperitoneal urethane (Sigma) $(1.25 \mathrm{~g} / \mathrm{kg}$. Each animal was inoculated in the conjunctival sac with $5 \mathrm{ml}$ of a solution containing faeces from infected bugs ${ }^{9} 33$. Twenty animals, similarly anesthetized, also received $5 \mathrm{ml}$ of a solution containing faeces from non-infected bugs. Forty additional animals were used as normal controls.

The heart rate was recorded, under ether anesthesia, before inoculation and every third day until day 42 post-inoculation. A Grass polygraph was used. The electrocardiographic signal from standard limb leads was digitized, stored in a Radioshack computer and played back for analysis (Interphase built in our laboratory) ${ }^{18}$.

In the inoculated animals, infection was demonstrated by xenodiagnosis after day 6 post- inoculation and at 3-day intervals until day 30 post-infection. Three infected animals and 3 sham-inoculated animals were randomly selected for histological studies at days 10, 15 and 19 post-infection. A total of nine hearts from infected animals were studied to demonstrate the presence of Trypanosoma cruzi. Histological studies were intentionally carried out, during this critical time window, because Trypanosoma cruziinduced myocarditis is maximal at this time ${ }^{345629}$. This experimental research was approved by the Scientific Commission of the Centro de Investigaciones Cardiovasculares of the University of Los Andes. Animals were treated in compliance with established international standards (Guide for the care and use of laboratory animals).

Statistical analysis. The baseline heart rate and the heart rate changes observed, in the three groups of animals, were analyzed by comparing intragroup and intergroup variations of the recorded heart rate at day 0 pre-inoculation and at three day intervals until day 42. The Friedman paired-test for series of paired interdependent variables was used to determine the presence of statistically significant intragroup differences at $p<0.05$. One-way analysis of variance with Bonferroni's correction was used to determine intergroup differences at $p<0.05$. The data are reported as mean \pm SD. 


\section{RESULTS}

The baseline heart rate of the three groups of animals was similar at day 0 pre-inoculation (Control: $379 \pm 27$ beats/min, mean \pm DS; Shaminoculated: $366 \pm 31$; Infected: $351 \pm 29$ ). In the animals inoculated with faeces from infected bugs, the heart rate began to increase by day 12 following infection $(375 \pm 31)$, reached the highest values between days $18(390 \pm 33)$ and day 21 $(403 \pm 33)$ and returned gradually to baseline by day $30(359 \pm 28)$. The heart rate changes recorded between days 12 and 27 (375 \pm 35 ) post-infection were significantly higher than those observed during the first eleven days postinfection and than those registered after day 27 $(p<0.05)$. The sham-inoculated animals and the normal controls had no statistically significant changes in their heart rates during the observation period (Figure 1).

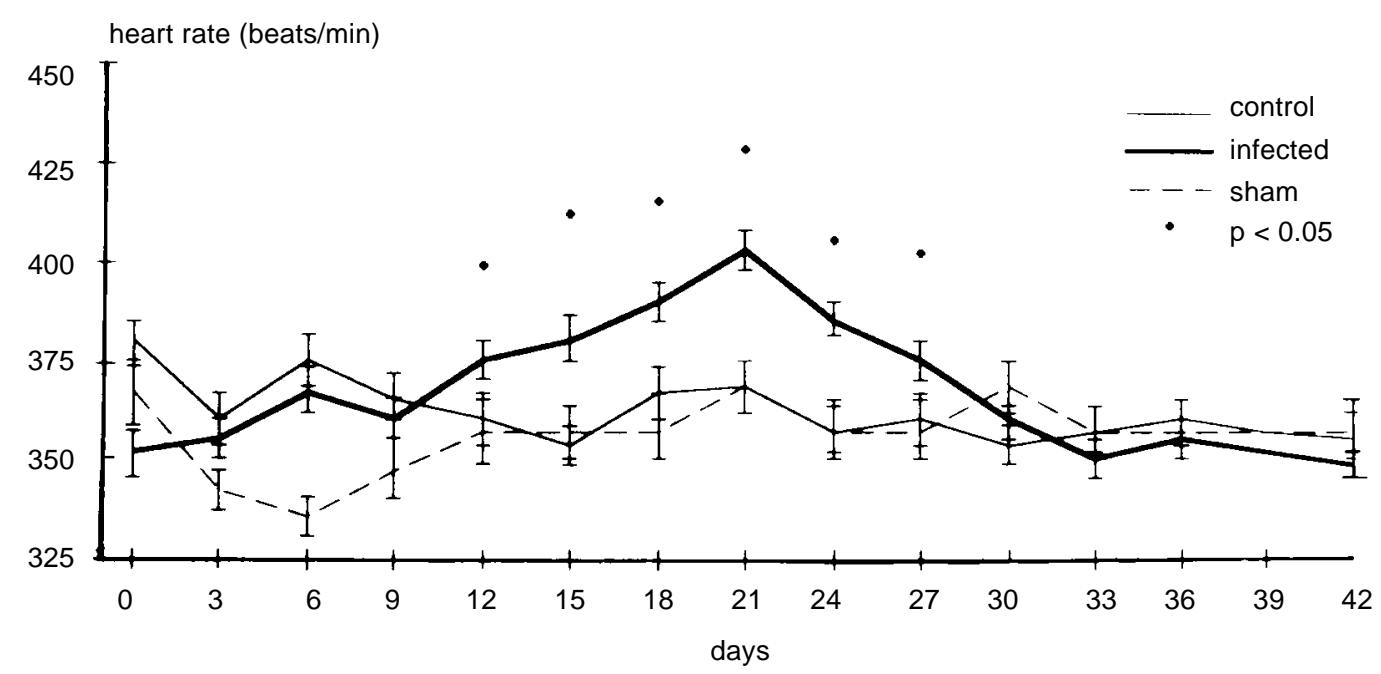

Figure 1 - Heart rate changes induced by T. cruzi obtained from bug faeces. At baseline (0), the heart rate of the three groups of animals was similar. In the infected animals, heart rate began to increase by day 12 following inoculation, reaching a peak between days 18 and 21 and returned to baseline by day 30 . These heart rate changes are statistically different from those observed in the sham-inoculated and normal animals. Values represent mean \pm sd.

Xenodiagnosis and histologic findings. Xenodiagnosis was performed in 18 of the 60 animals inoculated with parasites from faeces of infected bugs. It was positive in all of them (100\%). Histological examination of the nine hearts of the infected animals revealed the presence of variable degrees of diffuse myocarditis and numerous pseudocysts of amastigotes. It should be pointed out that, in the present investigation, these morphological studies were exclusively aimed to demonstrating the presence of the parasite in the myocardium of the infected animals. The hearts of the sham-inoculated animals presented no cardiac abnormalities.

\section{DISCUSSION}

The results of the present investigation have shown that in those animals, in which Trypanosoma cruzi infection was unequivocally demonstrated by xenodiagnosis and cardiac histopathology, the heart rate progressively increases, reaching a peak by day 21 after inoculation and returns to baseline by day 30 post-infection. Since the heart rate was recorded in all three groups of animals under similar experimental conditions, it is unlikely that the anesthesia with ether could be playing a significant role in the genesis of this transient sinus tachycardia. Moreover, the heart rate of the sham-inoculated animals and that of the normal controls did not vary significantly. Therefore, the above described heart rate changes of the infected animals cannot be 
attributed to the non-infected bug faeces or to any other extraneous material. Indeed, as has been demonstrated by several autopsy studies, the observed transient heart rate changes are time related to the presence of Trypanosoma cruziinduced acute myocarditis ${ }^{3456}$. Furthermore, the heart rate changes of the animals inoculated with bug-infected feaces are qualitatively and timely similar to those described, when laboratory animals are infected with Trypanosoma cruzi obtained from mouse blood ${ }^{18}$. It must be concluded, therefore, that irrespective of the source of the parasite and of the route of inoculation, Trypanosoma cruzi-induced infection is followed by a transient sinus tachycardia.

What is the mechanism responsible for these transient heart rate changes? The transient nature of the observed heart rate changes suggest indirectly that they could be secondary to the acute inflammatory process of the myocardium ${ }^{29}$ and, or to an enhanced cardiac sympathetic activity $^{161822}$. A previous study by our laboratory showed that, when adrenergic beta-blockers ${ }^{15}$ are given to rats with Trypanosoma cruzi-induced infection at the peak of the sinus tachycardia (days 18 to 21 after inoculation), the negative chronotropic changes are linearly and significantly related to the baseline heart rate. Furthermore, the absolute decrement in beats/min, provoked by adrenergic beta-blocker, was four times that of the non-infected controls. Moreover, when a similar protocol was applied to infected animals, which were in day 60 after infection, the heart rate response to the beta-blocker was now similar to that of non-infected controls ${ }^{15}$. Consequently, a possible explanation for the transient sinus tachycardia is an enhanced cardiac sympathetic activity, which would be more prominent during days 18 to 21 post-inoculation. An alternative explanation would be a partial and reversible damage to the cardiac parasympathetic neurons ${ }^{16}$ ${ }^{18}$. However, the heart rate responses to electrical stimulation of the distal portion of the vagus ${ }^{12}$ and to the administration of intravenous serotonin ${ }^{31}$, of rats with acute Trypanosoma cruzi infection (days 18 to 21 after inoculation), are not significantly different from controls. Furthermore, autopsy studies of humans ${ }^{126}$ that died from acute Trypanosoma cruzi infection and of laboratory animals experimentally infected with the parasite 8103032 have found no statistically significant reduction in the number of cardiac parasympathetic neurons.

Finally, It should be emphasized that very recent histochemical ${ }^{21}$ and morphological ${ }^{28}$ investigations of the cardiac cholinergic and adrenergic innervation of the hearts of infected animals, have demonstrated the presence of damage to these nervous fibers by day 34 postinoculation. In these studies, cardiac nervous damage was related to the intensity of the myocardial inflammatory process.

In summary, Trypanosoma cruzi infection provokes a transient sinus tachycardia, irrespective of the source of the parasite and inoculation route. The most likely mechanisms responsible for these heart rate changes are: the acute myocardial inflammatory process and an enhanced cardiac sympathetic activity. The effects of the parasite on the cardiac parasympathetic neurons are still a matter of intense controversy and research.

\section{REFERENCES}

1. Almeida-Ribeiro R, Lourenco Junior DM, Dias JC, Shikani-Yasuda MA, Chapadeiro E, Lopes ER. Intracardiac autonomic nervous system (ICANS) in a fatal case of acute Chagas' disease. Revista da Sociedade Brasileira de Medicina Tropical 26:35-38, 1993.

2. Amorim DS, Manco JC, Gallo L, Marin-Neto JA. Chagas' heart disease as an experimental model for studies of cardiac autonomic function in man. Mayo Clinic Proceedings 57(suppl):48-60, 1982.

3. Bestetti RB, Baroldi G, Sales-Neto VN, Soares EG, Oliveira JS. The usefulness of the resting EKG for characterizing acute Chagas' heart disease in the rat. International Journal of Cardiology 18:305-315, 1988.

4. Bestetti RB, Pinto LZ, Soares EG, Muccillo JG, Oliveira JS. Changes in electrocardiographic patterns at different stages of Chagas' heart disease in rats. Clinical Science 80:33-37, 1991.
5. Bestetti RB, Soares EG, Sales-Neto VN, Araujo RC, Oliveira JS. The resting EKG of Trypanosoma cruzi infected rats. Revista da Instituto de Medicina Tropical de São Paulo 29:224-229, 1987.

6. Blandon R, Edgcomb JH, Guevara JF, Jonhson CM. Electrocardiographic changes in Panamanian Rattus rattus naturally infected by Trypanosoma cruzi. American Heart Journal 88:758-764, 1974.

7. Brener Z. Contribuição ao estudo da terapêutica experimental da doença de Chagas. Tese de DocênciaLivre, Faculdade de Odontologia e Farmácia da Universidade de Minas Gerais, Belo Horizonte, 1961.

8. Caliari MV, de Lana M, Caliari ER, Tafuri WL. Cardiac plexus of dogs experimentally infected with Trypanosoma cruzi: I- inflammatory lesions and quantitative studies. Revista da Sociedade Brasileira de Medicina Tropical 28:13-17, 1995. 
9. Carreira JC, Jansen JC, Deane MP, Lenzi HL. Histopathological study of experimental and natural infections by Trypanosoma cruzi in Didelphis Marsupialis. Memórias do Instituto Oswaldo Cruz 91:609-618, 1996.

10. Chapadeiro E, Florencio RF, Afonso PC, Beraldo PS, Jesus PC, Junqueira Jr LF. Neuronal counting and parasympathetic dysfunction in the hearts of chronically Trypanosoma cruzi-infected rats. Revista do Instituto de Medicina Tropical de São Paulo 33:337-341, 1991.

11. Dávila DF, Bellabarbra G, Donis JH, Torres A, Rosell OJ, Figueroa O, Amaro M, Vasquez CJ. Cardiac autonomic control mechanisms in Chagas'heart disease. Therapeutic implications. Medical Hypothesis 4:33-37, 1993.

12. Dávila DF, Gottberg CF, Donis JH, Torres A, Fuenmayor AJ, Rosell O. Vagal stimulation and heart rate slowing in acute experimental chagasic myocarditis. Journal of the Autonomic Nervous System. 25:233-234, 1988.

13. Dávila DF, Gottberg CF, Torres A, Holzhaker G, Barrios $\mathrm{R}$, Ramoni P, Donis JH. Cardiac sympatheticparasympathetic balance in rats with experimentallyinduced acute chagasic myocarditis. Revista da Instituto de Medicina Tropical de São Paulo 37:155-159, 1995.

14. Dávila DF, Inglessis G, Dávila CAM. Chagas' heart disease and the autonomic nervous system. International Journal of Cardiology 66:123-127, 1998.

15. Dávila DF, Rossell O, Donis JH. Cardiac parasympathetic abnormalities. Cause or consequence of Chagas' disease. Parasitology Today 5:327-329, 1989.

16. Eckberg DL. Sympathovagal balance: a critical appraisal. Circulation 96:3224-3232, 1997.

17. Floras JS. Clinical aspects of sympathetic and parasympathetic withdrawal in heart failure. Journal of the American College of Cardiology 22:72-84, 1993.

18. Gottberg CF, Donis JH, Torres A, Fuenmayor AJ, Dávila DF. Heart rate changes in rats with acute chagasic myocarditis. Transactions of the Royal Society of Tropical Medicine \& Hygiene 82:851, 1988.

19. Higgings CB, Vatner SF, Braunwald E. Parasympathetic control of the heart. Pharmacology Review 25:119-155, 1973.

20. Koberle F. Cardiopathia parasympathicopriva. Munch Medicine Wochenschr 101:1308-1310, 1959.

21. Machado CRS, Caliari MV, Lana M, Tafuri WL. Heart autonomic innervation during the acute phase of experimental american trypanosomiasis in the dog. American Journal of Tropical Medicine \& Hygiene 59:492496, 1998.

22. Mathew NL. Parasympathetic control of the heart. In: Randall WC (ed) Neural control of the heart. University press, Oxford, New York p. 95-129, 1977.
23. Oliveira JSM, Marin-Neto JA. Editorial Note: Parasympathetic impairment in Chagas' heart disease. Cause or consequence? International Journal of Cardiology 21:153-156, 1988.

24. Packer M. The neurohormonal hypothesis: a theory to explain the mechanisms of disease progression in heart failure. Journal of the American College of Cardiology 20:248-254, 1992.

25. Randall DC, Randall WC, Brown DR, Yingling JD, Raisch JD. Heart rate control in awake dog after selective SA-nodal parasympathectomy. American Journal of Physiology 262:H1128-H1135, 1992.

26. Rocha A, Neves SA, Lopes ER, Macedo VO. Acute chagasic cardiopathy. A systematic study of the intracardiac excitatory-conduction and autonomic nervous systems in an autochthonous case in Acre. Revista da Sociedade Brasileira de Medicina Tropical 29:367-371, 1996.

27. Rossi L. Neuropathology of chronic chagasic cardiopathy: a diagnostic reassessment. Cardiovascular Pathology 5:233-239, 1996.

28. Sassoli Fazan VP, Lachat JJ. Qualitative and quantitative morphology of the vagus nerve in experimental Chagas' disease in rats: a light microscopy study. The American Journal of Tropical Medicine \& Hygiene 57:672-677, 1997.

29. Scorza C, Scorza JV. Acute myocarditis in rats inoculated with Trypanosoma cruzi: study of animals sacrificed between the fourth and twenty-ninth day after infection. Revista do Instituto de Medicina Tropical de São Paulo 14:171-177, 1972.

30. Souza MM, Andrade SG, Barbosa Jr AA, Macedo Santos RT, Ferreira Alves VA, Andrade ZA. Trypanosoma cruzi strains and autonomic nervous system pathology in experimental Chagas' disease Memórias do Instituto Oswaldo Cruz 91: 217-224, 1996.

31. Torres A, Dávila DF, Gottberg CF, Donis JH, Hoezaker G, Ramoni-Perazzi P, Bellabarba G. Heart rate responses to intravenous serotonin in rats with acute chagasic myocarditis. Brazilian Journal of Medical \& Biological Research 29:817-822, 1996.

32. Wong WC, Tan CK, Singh M, Yick TY. Ultrastructure of murine cardiac ganglia in experimental Chagas' disease. Histology \& Histopathology 7:371-378, 1992.

33. Zeledon R, de Trejos M, Chinchilla M. Experimental infection of mice with blood, culture and insect forms of Trypanosoma cruzi by different routes. Protozoology 111:95-101, 1977. 